Canadian Journal of Fisheries and Aquatic Sciences

Canadian

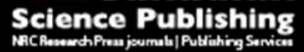

Journal canadien des sciences halieutiques et aquatiques

\title{
The effects of seasonal processes on size spectrum dynamics
}

\begin{tabular}{|r|l|}
\hline Journal: & Canadian Journal of Fisheries and Aquatic Sciences \\
\hline Manuscript ID & cjfas-2015-0468.R2 \\
\hline Manuscript Type: & Article \\
\hline Date Submitted by the Author: & $15-$ Feb-2016 \\
\hline Complete List of Authors: & $\begin{array}{l}\text { Datta, Samik; University of Warwick, Warwick Mathematics Institute } \\
\text { Blanchard, Julia; University of Tasmania, Institute of Amrine and Antarctic } \\
\text { Studies }\end{array}$ \\
\hline Keyword: & $\begin{array}{l}\text { size spectrum, marine ecosystem, seasonality, plankton bloom, SPAWNING } \\
<\text { General }\end{array}$ \\
\hline
\end{tabular}




\title{
The effects of seasonal processes on
}

\section{size spectrum dynamics}

\section{Samik Datta ${ }^{1 *}$ and Julia L. Blanchard ${ }^{2,3}$}

\begin{abstract}
The recent advent of dynamic size spectrum models has allowed the analysis of life processes in marine ecosystems to be carried out, without the high complexity arising from interspecies interactions within dense food webs. In this paper we use mizer, a size spectrum modelling framework, to investigate the consequences of including the seasonal processes of plankton blooms and batch spawning to the model dynamics.

A multispecies size spectrum model is constructed using twelve common North Sea fish species, with growth, predation and mortality explicitly modelled, before simulating both seasonal plankton blooms and batch spawning of fish (using empirical data on the spawning patterns of each species). The effect of seasonality on

\footnotetext{
1e-mail: * s.datta@warwick.ac.uk
} 
Keywords: size spectrum; marine ecosystem; seasonality; spawning; plankton bloom 


\section{Introduction}

2 The concept of the size spectrum, established in the pioneering work of Sheldon and

3 Parsons (1967), has initiated a whole branch of research in marine ecology. In aquatic

4 systems, neglecting taxonomy and looking only at organism weights, the abundance

5 of organisms is a negative power-law distribution of the individual mass (or equiva-

6 lently size), and plotting $\log ($ abundance) against log(mass) gives a roughly linear fit

7 with slope -1 (Sheldon et al. 1972; Platt and Denman 1978). This regular pattern ap-

8 pears to be robust, independent of the size scale which is investigated (within marine

9 systems, although less commonly in freshwater systems (see Sprules and Barth, this

issue)), and the linear relationship has been observed for phytoplankton (San Martin

et al. 2006; Huete-Ortega et al. 2010), zooplankton (Heath 1995: Zhou et al. 2009) and

fish spectra (Boudreau and Dickie 1992: Jennings and Mackinson 2003).

Within this broad pattern there is important seasonal variation caused by changes

4 in temperature, nutrient levels and turbulence. Such environmental factors can al-

5 ter abundances of plankton and/or larger organisms, influencing the intercepts and

slopes of size spectra over the year (Navarro and Thompson 1995; Mari and Burd

7 1998; Cózar and Echevarría 2005). The single biggest seasonal driver of variation in

8 size spectra is the phytoplankton bloom that occurs at some stage during the year

(Barnes et al. 2011), usually in the spring, although smaller blooms can also occur in

20 the autumn (see Truscott 1995; Findlay et al. 2006). The bloom is characterized by an

21 increase in the phytoplankton to 5 to 10 times its usual abundance (Gasol et al. 1992;

Navarro and Thompson 1995: Batten et al. 2003; Huete-Ortega et al. 2010), depending

23 upon the latitude and surrounding environment, before returning to a fairly constant

abundance for the rest of the year. This process can take place over several days or

over the course of weeks, and is followed by an increase in abundance of zooplankton

further along the size spectrum (Heath 1995), which in turn provides a larger food

source for fish larvae (Cushing and Horwood 1994; Mertz and Myers 1994). 
Spawning patterns are another important source of temporal variation in marine systems. It is well established that some fish species spawn only at certain times in the year, such as cod, sole and sprat (see e.g. Mertz and Myers 1994; Johnson 2000; Armstrong et al. 2001); this behaviour is to take advantage of the extra food abundance from annual phytoplankton plankton blooms, if Cushing's "match / mismatch" hypothesis is to be believed (Cushing 1975; Beaugrand et al. 2003). However, different species living under the same conditions have vastly different spawning patterns (see Figure 1 1 , and it is important to include in any reproductive model the range of strategies adopted by different species.

Dynamic size spectrum models are increasingly being used to understand structure and dynamics of marine systems, including the effects of fishing and climate change (Blanchard et al. 2012; Woodworth-Jefcoats et al. 2013) and inclusion of multispecies dynamics to address questions related to fisheries (Blanchard et al.2014; Spence et al., this issue). However, so far these models have simplified reproductive processes and focused on inter-annual changes in plankton levels.

Modelling reproduction in a size spectrum model has been accomplished in a nonseasonal setting before (e.g. Maury et al. 2007a; Hartvig et al. 2011; Law et al. 2012); in short, models generally used a fraction of the assimilated body mass from predation to produce eggs of a fixed weight, following the dynamic energy budget (DEB) theory of Kooijman (1986, 2009). This resulted in an influx of biomass at a fixed offspring weight in the spectrum, following the observation that regardless of fish species, egg size is fairly constant among many pelagic fish species (Ware 1975; Cury and Pauly 2000). Physiologically structured population models (PSPMs) often include pulsed reproduction, where pre-allocated mass is transformed into a batch of new cohorts at the beginning of each season (see e.g. Persson et al.1998; De Roos and Persson 2001). More recently PSPMs have allowed reproduction to occur over longer discrete time intervals (Huss et al. 2012: van Leeuwen et al.|2013). More complex individual-based size struc- 
tured models have incorporated seasonal reproduction dynamics, but either focused on a specific region geographically (Marzloff et al. 2009) or on consumer-resource dynamics without the effects of predation on consumers (De Roos et al. 2009; Sun and de Roos 2015).

A recent paper by Sainmont et al. (2014) used an ODE-model approach to investigate alternative strategies for seasonal reproduction (capital versus income breeding) in environments with varying feeding seasons and maturity weights. In short, income breeding allocates incoming mass directly to reproduction, whereas capital breeding stores reserves which may be used for spawning at a later time, independent of food availability. That paper found capital breeding to be the optimum strategy in higher latitude environments where food availability was more variable (with a sharp spike in springtime and lower levels outside of this period), with income breeding being advantageous for longer feeding seasons. For more details about capital and income breeding, see Jönsson (1997); Jager et al. (2008); Ejsmond et al. (2015).

Clearly a comprehensive simulation of the impacts of seasonality should include capital breeding, since this strategy can be both optimal theoretically (Sainmont et al.2014; Ejsmond et al.2015) and, more importantly, common empirically in seasonal environments (e.g. Lambert and Dutil 2000). However, the purpose of this manuscript is to conduct an initial exploration of the consequences, for the consumer size spectrum, of seasonality in both resource availability and consumer spawning times. Given this is an introductory analysis of the qualitative effects of these seasonal patterns on the dynamics and behaviour of consumer spectra, the focus will be on income breeding, perhaps the simplest representation of how energy is allocated between reproduction and growth in the face of seasonal variation in resource availability, as modelled previously (Law et al. 2012; Blanchard et al. 2014; Scott et al. 2015). We expect that the results of this analysis will guide future work on including and evaluating the impact of capital breeding behaviour on seasonal patterning of the consumer spectrum. 
1 This study builds upon previous work on the timing of larval hatching, where a fixed 2 temporal "background" spectrum was set up, and then cohorts born at different times 3 were followed to calculate the best time of year to be born in terms of fast growth and low mortality, without modelling the dynamical feedbacks to the size spectrum (Pope et al. 1994). That paper found it was best to be born at or before the peak in plankton abundance, to avoid increased predation mortality from the fixed wave reaching the size range of predators of newborns, and to stay ahead of this wave for the rest of the year.

9 Here we introduce seasonality to a previously published multispecies size spectrum

\section{Methods}

\section{Setting up the size spectrum model}

To model seasonal reproduction of pelagic predators (typically fish) and plankton blooms, a modified version of the previously published mizer package in $\mathrm{R}$ is used (Scott et al. 2015), which uses the work of Blanchard et al. (2014) as its basis. The 
1

model of that paper is a representation of the North Sea community, with parameters calibrated to observed catch and effort data for the North Sea over the period 19851995. Hence, this study is in part an extension of the work presented in Blanchard et al. (2014), and will necessarily be conditioned by the structure and assumptions of that work. Specifically:

1. model responses to both the addition of seasonal affects and to changes in fishing pressure will be conditioned by how this set of North Sea species was harvested over the calibration period 1985-1995;

2. the calibration procedure used in the 2014 study will have a significant effect on the role that changes in egg production can have in this new study; more detail on this will be provided in the description of how reproduction is represented in this model.

The model presented here consists of two parts: a resource spectrum and a multispecies consumer spectrum, both of which are dynamic and time-dependent. Here, "consumer" refers to organisms within any of the fish species spectra, and the aggregation of all species spectra is labelled the "community" spectrum. The "resource" spectrum comprises both the phyto- and zooplankton communities. We summarise the model used in the following subsections; for further information on the equations and parameters used, see Table 1; default parameter values are used for all simulations, as in the mizer vignette (Scott et al. 2015, page 67). Values for parameters related to seasonal spawning and plankton blooms are given in Table 2 . Supplementary material S1 describes how to add seasonality to the mizer model, along with a link to the $\mathrm{R}$ code used; what follows here is an in-depth look at the model structure. 


\section{Consumer spectrum}

2

The model uses the McKendrick-von Foerster equation as its backbone for growth through the spectrum (Andersen and Beyer 2006; Blanchard et al. 2009: Law et al. 2009; Datta et al. 2010). Organisms feed upon smaller organisms in both the resource and consumer spectra according to a Gaussian feeding preference function (4), commonly used in modelling predation in marine systems (Benoît and Rochet 2004; Andersen et al. 2009; Law et al. 2012). Organisms die either from being eaten by larger organisms, or from natural causes (this encompasses starvation and natural mortality; see Table 1). Starvation has often been cited as a source of high mortality for fish (although results are not entirely conclusive; see Anderson (1988)), and is included as a function which becomes more severe as the growth rate of consumers drops; it decreases exponentially with body size, as larger body size makes starvation less likely (Duarte and Alcaraz 1989: Leggett and Deblois 1994).

Since the weight of eggs spawned from marine teleost fish lie in a narrow range around 1mg (Ware 1975: Cury and Pauly 2000), recruitment to a single fixed egg weight (of $1 \mathrm{mg}$ ) in the spectrum is used. Reproduction can either be constant or over a limited period of time across the year. The reproductive rate is dependent on the predation rate, in keeping with the dynamic energy budget methods (Kooijman|2009) commonly used in size spectrum models to allocate incoming mass to somatic and reproductive mass (e.g. Maury et al. 2007a; Blanchard et al. 2011). Thus we consider mature individuals to be income rather than capital breeders, the latter having spawning that is relatively independent of current prey availability but strongly dependent upon lagged average availability (Sainmont et al. 2014). The physiology of egg production is not explicitly modelled, and simple size-based fecundity is assumed.

The incorporation of reproduction into the model follows the mizer model (Scott et al. 2015, equation (3.10)), although here we also include a time-dependent term to allow for seasonal spawning. This time-dependent term generates temporal change for both 
1 seasonal spawning and plankton pulses, and is adapted from previous work (Pope 2 et al. [1994: Datta|2011). It has the form

$$
s\left(v_{i}, t_{i}, \psi_{i}, t\right)=\frac{e^{\left(1-\psi_{i}\right) v_{i} \cos \left(2 \pi\left(t-t_{i}\right)\right)}}{I_{0}\left(\left(1-\psi_{i}\right) v_{i}\right)},
$$

3

4

and is a dimensionless term dependent on time $t$, where $t_{i}$ is the time of the pulse peak, and $v_{i}$ describes the severity of the peak (i.e. how short and sharp spawning or the bloom is over the year). For reproduction, the two parameters $t_{i}$ and $v_{i}$ are fitted to empirical data on spawning patterns of the twelve fish species modelled (Figure 1), while for resource blooms the parameters are estimated from observed data (see Table 2). $I_{0}$ is the modified Bessel function of order 0 , and is a normalising factor which fixes the total mass allocated by an individual to spawning over a year for all $v_{i}$. In other words, as $v_{i}$ increases, the duration of spawning becomes shorter, giving a narrower Gaussian-shaped peak (the numerator of (1)). However, a higher $v_{i}$ causes the denominator $I_{0}$ to decrease, increasing the height of the peak to give the same area under the curve (i.e. an equal number of eggs). Thus, altering spawning duration for a species produces an equivalent amount of offspring (for equal feeding rates). In Supplementary Material S2 $s\left(v_{i}, t_{i}, \psi_{i}, t\right)$ is plotted for a range of values of $v_{i}$ to illustrate this.

We introduce the following terminology to describe aspects of the reproductive process in the model:

- Individual reproductive investment: the proportion of incoming mass that an individual uses for egg production (11). This depends upon an individual's species, its weight $w$ and time $t$, and is limited by incoming biomass at each time step.

- Population reproductive investment: the aggregated population production of eggs for a species (13). This is summed over all mature individuals in the species (the integral term of (13)), and takes into account production efficiency and the 
sex of individuals (Scott et al. 2015, section 3.5).

- Recruitment: the total number of eggs feeding into the "newborn" weight bin of a species at time $t$, which takes into account the maximum level of recruitment for each species (14).

Given the parameterisation in Blanchard et al. (2014), we expected that recruitment for all species would remain at or close to their maximum $\left(R_{\max . i}\right.$ in (14) $)$ for all times and scenarios, and this expectation was borne out in practise during initial runs of the model. As a consequence, behavioural patterns observed in model output of this study are interpreted in terms of the shifts in growth and mortality rates that are produced by introducing seasonality.

The weight parameter $\psi$ is the allocation of incoming mass to reproduction rather than somatic growth, which incorporates both the maturation weight and asymptotic weight of a species (Table 1, equation (9)). Without the $(1-\psi)$ terms, equation (1) is the von Mises function used by Pope et al. (1994), and for plankton blooms we set $\psi_{p}=0$ to give this form. The $(1-\psi)$ terms are included for spawning to limit the growth of organisms close to their asymptotic weight, by forcing them to spawn less seasonally as their weight increases. This assumption is not realistic, but within this modelling framework it is a necessary addition for growth behaviour of the species to match the fitted growth curves of Blanchard et al. (2014). Those curves implicitly assumed constant reproduction as a fraction of incoming mass, and to disentangle the process would require an entirely novel parameterisation for the growth of all species, and was beyond the scope of this work. The assumption is discussed more in the Discussion.

Using empirical data on the monthly spawning rates for the twelve fish species simulated, von Mises distributions (Pope et al. 1994) are fitted to each species to give the shape of the reproduction curves (Figure 1 ). 
In Supplementary Material S3, a methodological derivation for the reproduction function used in mizer (Scott et al. 2015) is shown, using similar methods to the derivation of the deterministic jump-growth model (Datta et al.2010); in short, it is assumed that the amount of weight lost in each spawning event is quite small, leading to a firstorder approximation which can potentially be incorporated into any McKendrick-von Foerster equation to simulate both capital and income breeding processes.

Fishing is incorporated as in Blanchard et al. (2014); relevant equations are shown in Table 1. equations (17) and (18). In summary, fishing mortality is size- and speciesspecific, which can remain constant throughout the simulation or can vary at specified times. A standard fixed logistic selectivity function is used to describe the ability of the fishery to catch each species. Parameters are selected so that baseline fishing efforts give realistic distributions for the species spectra, using stock assessment data from the period 1985-1995 (www.ices.dk). Some parameters are non-species-specific and are assumed to be the same for all species. For a full list of parameters and values see Tables S2 and S3 of Blanchard et al. (2014).

\section{Resource spectrum}

For simplicity, the processes driving the dynamics of phytoplankton and the acquisition of energy from nutrients and light are not explicitly modelled here (see Moloney and Field 1991; Fuchs and Franks 2010). Instead, it is assumed that organisms in the resource spectrum can be preyed upon by organisms in the consumer spectrum, but replace themselves using a semi-chemostat function for replenishment to a carrying capacity. Models have tested the response of the size spectrum to bottom-up perturbations before, by increasing the height of the phytoplankton size classes uniformly for a short period of time (Maury et al. 2007b; Blanchard et al. 2011). Here a similar approach is taken.

Following the approach of Pope et al. (1994) the seasonal size-time resource spectrum 
1 is characterised by the von Mises time distribution (1), as well as predation by the 2 consumer spectrum, and the equation for the dynamics of the resource spectrum is 3 given by

$$
\frac{\partial N_{R}(w, t)}{\partial t}=\left(\omega+(1-\omega) s\left(v_{p}, t_{p}, \psi_{p}, t\right)\right) \cdot \mathbf{N}
$$

4 The left hand side denotes the change over time in the resource spectrum $N_{R}$, which 5 is a function of weight $w$ and time $t . \mathbf{N}$ is the shorthand introduced for the dynamics 6 of the resource spectrum of Scott et al. (2015, equation (3.15)). The preceding term 7 differentiates our model from the original; $\omega$ sets what proportion of the spectrum is 8 present independent of the bloom, and $s\left(v_{p}, t_{p}, \psi_{p}, t\right)$ sets the shape of the bloom (there 9 is no weight dependent behaviour for the bloom, so $\psi_{p}=0$ for all size classes in the

resource spectrum). Resource abundance thus remains relatively constant for most of the year but then, dependent on the value of $v_{p}$, may "bloom" for a short period; that is, the entire resource spectrum increases in abundance, whilst keeping the same gradient, before relaxing back to its original level.

Parameters are chosen to reflect the likely timing and abundance of blooms in real systems (Gasol et al. 1992; Huete-Ortega et al. 2010). The increased abundance affects the feeding rate, and thus growth, of consumers able to take advantage of the increase in biomass in the system. The full form of (2) is given in Table 1, equation (19).

The combination of bottom-up and top-down feedbacks is what the simulations focus on, and is a natural progression from the previous work by Pope et al. (1994) where the entire size spectrum was specified by a von Mises distribution; here the interplay between differently timed seasonal processes is what drives the dynamics to produce qualitatively different community spectra. Differences in the two analyses are further reviewed in the Discussion. 


\section{Numerical simulations}

2

To numerically solve the dynamics of the model, the system of resource and fish species spectra is initialised using default values from Scott et al. (2015). This is taken as the initial distribution for all of the simulations. The resource and fish species spectra through time are then calculated, both with and without seasonal plankton blooms and seasonal spawning (henceforth referred to as seasonal and non-seasonal systems respectively).

The growth trajectory of an individual is tested using the method of characteristics (see Kot 2001, p.393 onwards). The body mass of a newborn through time is calculated by solving

$$
\frac{d w}{d t}=g_{i}(w(t))
$$

where $g_{i}(w(t))$ is taken from (10). The method of characteristics is employed to calculate the growth trajectories (3) of offspring of the different species over the course of a lifetime, as in previous work (Law et al. 2009: Rochet and Benoît 2012). In short, the starting mass of the individual is set at the mass of a newborn (1mg). Then, at each timestep the growth rate of the individual is set at the weight bin that the individual occupied, and the new mass calculated. By tracking this mass through time, we calculate how quickly organisms grow in non-seasonal and seasonal spectra.

The effect of seasonal reproduction on the dynamics of the consumer spectrum is investigated, to simulate the spawning behaviour of twelve North Sea pelagic fish species (Figure 1). A fixed resource and community spectrum, which included waves of abundance from phytoplankton blooms, was previously studied, without dynamical links between growth, mortality and reproduction dynamics (Pope et al. 1994). We extend this model framework by making both spectra fully dynamic, and including species-specific seasonal spawning. The growth of individuals within both nonseasonal and seasonal systems are compared; this consists of growth within the spec- 
1 trum, behaviour of the community spectrum slope (calculated by fitting a linear model 2 to the plot of number density against weight, between $1 \mathrm{~g}$ and $10 \mathrm{~kg}$, using a natural 3 logarithm), and fishing yields over time.

4 All simulations are carried out using $\mathrm{R}$ (2015). For each simulation the spectrum is 5 allowed to run for 500 years with weekly time steps, so that a steady state for the non6 seasonal system is reached, and the seasonal system has extremely similar patterns 7 between years, before analyses are carried out.

\section{${ }_{8}$ Results}

\section{The size spectrum with non-seasonal and seasonal processes}

The size spectra at the end of 500 years under both non-seasonal and seasonal conditions are shown in Figure 2. The community spectrum (averaged over a year) is similar for the non-seasonal and seasonal systems (Figure 2a). In either case, the community spectrum rapidly settles down to a ridged uneven shape above $10 \mathrm{~g}$, caused by the range of asymptotic sizes reached by the twelve species. This shape was also noted previously by Blanchard et al. (2014) when running the system to steady state. There exists a discontinuity in the gradient of the slope at the boundary between the resource and consumer spectra where offspring are born, consistent with similar previous studies (Blanchard et al. 2011). The shapes of the community spectra can be better understood by examining the individual species spectra (Figure 2b), where the species grow to different asymptotic weights; this leads to the irregular shape of the community spectrum. Both the non-seasonal and seasonal species spectra are visually similar, and hence only the seasonal system is plotted here.

Although the annual average of both community spectra appear similar, within a year there is much variation in the species spectra in the seasonal system. This is shown in 
1 Figure 3, where densities at size are plotted relative to the non-seasonal steady state 2 spectrum. At the low end of the species spectra there are high variations in abundance, 3 due to the uneven spawning patterns of the species. A wave-like pattern propagates 4 through the species spectrum, as extra biomass from the resource bloom allows for faster growth of the smallest individuals in the spectrum, leading to a drop in number density in the smallest size classes and increased number density further along the size spectrum. These waves are damped at larger weights, as organisms undergo growth, death and reproduction through the spectrum, leading to a smoothing effect due to lowered biomass. At the right end of the spectrum the ratio for some species becomes very large or small due to tiny abundances at high weights in both spectra, so that small variations have large impacts. However, there are two groups of species with different patterns. One that has lower abundance density at largest sizes (sprat, dab, herring, gurnard) and the other with higher densities at large sizes (e.g. sandeel, sole, plaice, haddock, cod, saithe) relative to the non-seasonal model. This is an emergent result of the model due to faster growth and larger size at age reached for the latter group of species (Figure 4) whereas, for the former group, growth was either very similar or lower.

\section{Growth within seasonal systems}

In the non-seasonal system, growth curves over lifetimes were previously cross-validated with empirically fitted von Bertalanffy growth curves for each species (Blanchard et al. 2014). Comparison of growth in a seasonal versus non-seasonal system also reveals increasing temporal variation as fish become mature (Figure 4). Somatic growth is slower during the spawning period than the rest of the year. Species with narrower periods of spawning (see Figure 1) have less smooth growth curves; for example, compare the trajectories of cod and sole, which have highly seasonal spawning, with those of grey gurnard and Norway pout which spawn more evenly throughout. The overall 
growth over several years is similar to the non-seasonal system, with the same asymptotic masses being reached; this is due to the setup of the reproduction function (1), which makes spawning less seasonal as the asymptotic weight is reached.

The growth rate of a mature individual is shown in Figure 5, compared with a nonseasonal spawner. Initially reproductive effort is low, so the majority of biomass is used for somatic growth. Hence the gradient of the growth is steeper than for a nonseasonal spawner, whose growth rate is relatively constant over the whole year. As the reproductive period begins, overall growth decreases, and drops to zero around time $t=0.35$. Negative growth is not permitted in the model (as we are using income breeding), and while spawning is near its peak growth remains at zero, with all incoming mass being allocated to egg production. Around $t=0.75$ growth increases again, mirroring the von Mises spawning distribution closely. If a capital breeding function were used (i.e. making the somatic growth rate (10) and egg production (11) independent of each other) there would be the possibility for individuals to lose weight over the reproductive period, which would depend upon the rates of growth and spawning. In laboratory studies body mass has been observed to decrease if the mass lost in spawning is not compensated by the biomass assimilated through predation (Wootton 1977; Lambert and Dutil 2000), and the condition factor (related to weight at length) of fish has been shown to drop post-spawning (Le Cren 1951; Pedersen and Jobling 1989).

\section{Size spectrum properties in seasonal and fished systems}

The effect of seasonality on the community spectrum slope is shown in Figure 6 a The initial slope is approximately -1.65 (this is maintained under baseline fishing effort). After fishing intensity is doubled the slope for both seasonal and non-seasonal systems decreases to around -1.9. The non-seasonal system settles to a steady state rapidly, while the seasonal system oscillates at an average slightly above this value, 
1 with a cycle of one year, owing to seasonal processes occurring at the annual timescale. 2 Halving fishing effort leads to an increase in the slope of the spectrum due to a lack of 3 fishing mortality for fish on the right hand side of the spectrum, reaching around -1.5 4 for both systems; the slope in the seasonal system oscillates around an average value slightly below that observed in the non-seasonal system. These qualitative responses 6 of the slope to changes in fishing effort should be regarded as particular to our North Sea model, as they are conditioned by how our model represents the species-specific interplay between fishing effects and the growth pulse driven by the resource bloom.

At baseline fishing effort, yields for seasonal systems tend to be lower than nonseasonal systems, and peak around the non-seasonal yield (Figure 6b). This is due to the long-term distribution of the seasonal community generally having a higher abundance of smaller individuals but fewer large individuals, resulting from the effect of seasonal processes on growth of individuals to the larger size classes (Figure 7).

After fishing efforts are doubled yields initially spike to around twice the original quantity; however, in the following years yields quickly drop, as the increased mortality from fishing forces the community spectrum into a steeper shape, with lower abundance of larger fish (Figure 6b). Yields settle at about their original quantity within ten years, despite fishing pressure remaining twice as high. The opposite behaviour is seen when fishing intensity is halved; an initial drop in yields is followed by an gradual increase (due to lower mortality rates for mature fish leading to a more abundant community), settling at a value of 2.95Mt per year, slightly lower than at baseline effort (3.58Mt per year). Seasonal yields follow the same pattern as non-seasonal systems, although they oscillate around a lower mean value; only at oscillation peaks are yields roughly equivalent to the non-seasonal spectrum, and at the troughs they are approximately $80 \%$ of the non-seasonal yield. Increasing fishing effort in seasonal systems makes the variability in yields greater (comparing the difference in peaks and troughs 
between double and half fishing effort in Figure 6b).

However, integrated across the entire year, whichever fishing strategy is picked, the ratio of the seasonal to non-seasonal yields is close (approximately 93\%). This is ultimately due to the fact that in the region of parameter space the model occupies juvenile production is fairly constant between years (due to recruitment being more or less equal for non-seasonal and seasonal systems), but adult population densities are more often lower for seasonal than for non-seasonal spectra, resulting in lower fishing yields.

\section{Discussion}

Seasonal processes induce time-varying behaviour in the size spectra for individual species, with markedly different intra-annual growth for mature individuals. Although the aggregated community spectra remain visually similar for both seasonal and non-seasonal systems, analysis of these communities reveals key differences. The spectrum slope is more varied in seasonal systems, while fishing yields are up to $20 \%$ lower than under non-seasonal conditions during the year. In the seasonal system, increased fishing effort amplifies the peaks and troughs in the species size spectra, and hence the yields become much more variable through time (Figure 6b). In aquatic systems, increases in fishing effort have led to a shift towards faster growth rates which have previously been shown to cause increased temporal variability in production and fisheries yields (Blanchard et al. 2012). Arguments about balanced harvesting have also been made on the basis that fisheries size-selectivity affects the stability of size spectra and yields (Law et al. 2012) but this has yet to be investigated in the context of seasonal dynamics. Seasonal processes may thus have important implications for conclusions about fisheries management.

Compared to the value of -1 often seen in aquatic systems (e.g. Boudreau and Dickie 

1992; San Martin et al. 2006; Zhou et al. 2009) the slopes observed here are steeper; 2 however, heavily exploited systems have been shown to produce steeper slopes in 3 the past, due to fishing-induced truncation of the spectrum (Rice and Gislason 1996: 4 Blanchard et al. 2005). Seasonality led to a higher variability in the community spec5 trum slope than in its absence. Spawning strategies ranged from matching closely 6 with the timing and duration of the plankton bloom (e.g. sole and Norway pout in 7 Figure 1) to those spawning far away from the bloom (e.g. sandeel). However, the

balance of matches/mismatches of spawning and blooms does not account for the variation in slopes. Rather, within-year variation was due to the interplay between increased growth of smaller individuals caused by the annual plankton bloom, leading to a qualitatively different community spectrum with varied intra-annual dynamics but fairly similar inter-annual behaviour. We were aware that the region of parameter space that the model occupied had high levels of recruitment, with $R_{i}$ close to $R_{\max . i}$ for all species and times (14), and this limited the effect that seasonal reproduction had on the species spectra (as changes in recruitment were extremely minor over the course of a year). In reality density-dependent recruitment is an important factor in constructing size spectrum models, and requires a more in-depth approach in future (Andersen et al.2016, pages 18-19).

The resource bloom provided the majority of the changes in slope in this study. It was observed that, regardless of what upper and lower weight limits were chosen when calculating the slope, the qualitative behaviour when altering fishing effort was the same (as in Figure 6a). $1 \mathrm{~g}$ and $10 \mathrm{~kg}$ were chosen here as representative of the community. Altering these could affect the magnitude of shift in average seasonal slope compared to the non-seasonal slope, but the overall trend of steeper slopes with increased fishing persisted regardless.

Adding seasonality induced waves of biomass which moved up the species spectrum, as growth rates and offspring populations rose and fell throughout the year (Figure 3). 
1 There was a peak in biomass in offspring at the appropriate spawning peak from Fig2 ure 1; however, this was not as pronounced as the dip in biomass during the plankton 3 bloom, due to the increased growth rate of newborns caused by a more abundant food 4 supply in this period. Waves of abundance have been observed in previous models 5 (Law et al. 2009; Datta et al. 2010) when parameter values were chosen which desta6 bilised the steady state distribution. Adding a plankton bloom has a similar effect, 7 as organisms whose feeding range lies within the plankton spectrum are subject to 8 higher growth rates (Benoît and Rochet 2004; Maury et al. 2007a). Here it was ob9 served that seasonal forcing via the reproductive process also pushes the system away - from the steady state. With both plankton blooms and time-dependent reproduction occurring simultaneously, departures from the well-established power-law distribution (Sheldon et al.1972) are expected.

As expected, the general trend was for slopes to have a steeper gradient as fishing effort increased, due to higher mortality on organisms with higher mass (Figure 6a). 15 Interestingly, doubling fishing effort initially gave higher yields but these quickly de16 clined to a level similar to that provided by the baseline effort; halving effort had 17 the opposite effect, with an initial decline before increasing, with an asymptote of a 18 slightly reduced yield compared to baseline effort (Figure 6b). Upon investigation, 19 the cause was not shifts in the biomass of newborns, which was not significantly perturbed. Rather, the total biomass of the larger fish (the segment of the spectrum targeted by fishing) moved to different levels under the new fishing regimes, with doubled effort leading to a decrease in the biomass of larger fish and halved effort leading 23 to an increase. We stress that many of the model parameters of mizer are derived us24 ing the baseline fishing effort (time-averaged estimates over 1985-1995), so we do not 25 draw heavy conclusions from this result, except that doubling these values in the long26 term produced yields more consistent with the flat part of a yield curve (they did not 27 increase much) but carried a greater impact on the community size spectrum. 
In all cases (baseline, doubled or halved effort) seasonality led to yields fluctuating near the non-seasonal value at their peak, but with a lower average and troughs around $80 \%$ of the non-seasonal yield. It is perhaps not surprising that the nonseasonal system set the upper limit for yields, as for both systems recruitment was fixed by (14); with species-specific fishing pressure and asymptotic sizes, these factors resulted in a similar upper limit for the number of mature individuals in the community for seasonal and non-seasonal systems. Future work on the parameter sensitivity and uncertainty (Spence et al., this issue) is needed to elucidate the trade-offs in yield that result under different environmental conditions and management strategies. It is well known that fish stocks greatly fluctuate intra-annually (Horwood et al. 2000), and the simulations here show that assuming a non-seasonal system means higher yield predictions than when incorporating seasonality. For more accurate fisheries management, including time-dependent processes such as spawning could help improve the predictive powers of models to judge expected catch sizes throughout the year. This model could be used in conjunction with other operating models as part of management strategy evaluation to assess consequence of both short-term changes in seasonality as well as longer term environmental variability and change.

Size-based models have commonly divided incoming biomass from the predation process into somatic growth and egg production (De Roos and Persson 2002; Maury et al. 2007a; Kooijman 2009; Blanchard et al. 2011; Hartvig et al. 2011). We followed the same method here (Scott et al. 2015, section 3.4), but importantly allowing spawning to take place over limited times of each year. This is a natural step forwards from the early theoretical analysis of Pope et al. (1994), who used a static spectrum to investigate the growth and survival trajectories of cohorts born at different times of year. While we have not tested the success of different spawning techniques here, we have laid important groundwork in providing a more realistic framework in which the importance of spawning strategy in maximising cohort growth and maturation can be investigated. Having said that, there are several important caveats which could guide 
further developments.

An assumption introduced for convenience was to make spawning less seasonal as the asymptotic weight of an individual was approached. This limited the growth of species to empirically reasonable values; however, in reality seasonally spawning species retain seasonality, even at the largest size classes. This explains the similarity between the steady state species size spectra in the seasonal and the non-seasonal scenarios (Figure 2). Older individuals make a relatively large contribution to overall population fecundity, and hence the effect of spawning seasonality (as currently depicted in the paper) on species dynamics may well be under-emphasized. Hence, an important part of the follow-up work would be to incorporate more realistic growth functions for seasonally spawning species, such that both seasonal reproduction and a realistic upper body size for each species can be achieved.

Quantification of the size and timing of the plankton bloom was illustrative for the model. These factors are not constant globally, and are affected, for example, by latitude, temperature and hydrodynamics, as well as natural inter-annual variability. Here a single set of parameters was selected for the model; the peak of the bloom was around 6 times the abundance of outside the bloom period, and the bloom lasted around 7 weeks, following temporal data on plankton abundance (Gasol et al. 1992. Huete-Ortega et al. 2010). Many empirical studies sample phyto- and zooplankton spectra, but far less commonly within a single year to investigate intra-annual variation in abundance (see studies summarised in Sprules and Barth, this issue); a wide literature search revealed a broad range of values for this ratio (see e.g. Menzel and Ryther 1960: Navarro and Thompson 1995; Batten et al. 2003).

Real systems show greater variation in growth rates when observations are recorded without averaging results temporally or spatially (e.g. Heath 1995; Barnes et al. 2011). In reality reproduction is sometimes subject to spatial and temporal variation, and is independent of instantaneous growth (capital as opposed to income breeding, see 
1 Jönsson 1997; Jager et al. 2008; Sainmont et al. 2014). Such a reproduction function 2 should be both weight-dependent (Wootton 1977; Duarte and Alcaraz 1989; Blanchard 3 2000) and time-dependent, depending on the species (Figure 1). This is not to say that 4 food supply does not affect reproductive rate in the long term; studies have shown 5 correlations between rations received by fish and egg production (e.g. Wootton 1977). 6 An in-depth modelling of the physiology of marine organisms would be required for 7 the robust modelling of egg production from food intake, and although it is beyond 8 the scope of this work, would be of future interest.

Differences in model assumptions can affect the coexistence and stability of multispecies spectra models. For example, recent models (incorporating non-seasonal reproduction) have used random coupling strengths between species until stability was established (Hartvig et al. 2011), senescence mortality (Maury and Poggiale 2013), or density dependent stock-recruitment as in this model (although here model behaviour was explored in a part of parameter space where recruitment was largely independent of density; see also Andersen and Pedersen 2010). The adoption of different spawning strategies could be an important process for the division of energy amongst competing species and adaptation to different environmental conditions (Sherman et al. 1984; Longhurst 1998).

We used an "income" breeding method here, where biomass from predation is immediately converted to offspring, as in many size spectrum models (e.g. Blanchard et al. 2011; Hartvig et al. 2011; Law et al. 2012), hence weight loss was not possible. Some models have enabled organisms to lose weight during reproduction; for example, Persson et al. (1998) constructed a PSPM that incorporated a discrete reproductive period once a year, where all offspring for that year were produced at the same time in the spring. For this, "reversible mass" was built up over the rest of the year which could be lost in reproduction (or used for metabolism in the case of low food supply), as opposed to "irreversible mass" which made up the bones and organs and was 
assumed not to decrease.

We assume income breeding is a reasonable simplification for what has been presented here: an initial exploration of the consequences of seasonality in resource availability for the consumer size spectrum. It is not an ideal representation for all fish species but can be justified on the grounds of simplicity in integration into the mizer model. For capital breeding species, it is very common for females to lose 5 to $20 \%$ of their body ¿weight during the reproductive season from egg loss alone (Wootton 1977; Lambert and Dutil 2000). Weight losses due to behavioural changes during breeding can be similar for males, particularly for species that engage in some form of parental care. In freshwater species, spawning times of capital breeders are ordered around the annual production in ways that suggest some trade-off between optimization of feeding opportunities and minimization of competition (Shuter et al.|2012).

Thus, a useful extension of the analysis would be to include capital breeding in the model and to evaluate how results are affected, in such a way that it maintains both empirical accuracy and model simplicity; as such, the growth and reproduction functions must be made independent. Organisms must be allowed to lose weight across timesteps (which is not currently feasible), and as these losses may be significant, the current method of including reproduction (which is derived systematically in Supplementary Material S3) may no longer hold (as one assumption is that the amount of weight lost in a single reproductive event is always small relative to the size of the organism).

Including capital breeding in the model would likely have the effect of exaggerating the effects of seasonality. At the moment peak spawning is limited by food intake (as demonstrated by the growth curve in Figure 5); with capital breeding the growth curve would be able to have a negative slope as outgoing mass as eggs is greater than incoming mass from food. Hence the waves of biomass moving up the spectrum could become larger. Simulations of the timing of the pulsing (both resource pulse and re- 
1 productive pulse) could potentially inform empirical studies, such as when the most 2 meaningful snapshot(s) should be taken within a season to observe seasonal processes 3 (see Sprules and Barth, this issue; de Kerckhove et al., this issue) for a related discus4 sion).

5 There is still further theoretical and empirical work needed to understand the effects of seasonality on size spectrum processes, and the consequences for fishing yields, as well as the feedback between increased fishing mortality and recruitment in seasonally spawning species. What has been presented here is a first step towards more general approaches to simulating seasonal processes in a variable environment.

Acknowledgements: SD was supported by a NERC-CASE PhD studentship "A mathematical analysis of marine size spectra" with additional support from Cefas, and is currently funded by the UK Department of Health. JB acknowledges support from he Natural Environment Research Council and Department for Environment, Food and Rural Affairs (grant number NE/L003279/1, Marine Ecosystems Research Programme). We thank Richard Law, Gustav Delius, Michael Plank and Ken Andersen for discussion and comments on earlier versions of this work. We also thank the referees for their useful comments upon receiving earlier drafts of the manuscript. In particular, the editors Henrique Giacomini and Brian Shuter gave detailed and insightful feedback, and we are extremely grateful for all their help in the preparation of the manuscript.

\section{References}

Albert, O. (1994). Biology and ecology of Norway pout (Trisopterus esmarki Nilsson, 1855) in the Norwegian Deep. ICES Journal of Marine Science, 51(1):45.

Alheit, J. (1988). Reproductive biology of sprat (Sprattus sprattus): factors determining annual egg production. ICES Journal of Marine Science, 44(2):162. 
Andersen, K. H., Beyer, J., and Lundberg, P. (2009). Trophic and individual efficiencies of size-structured communities. Proceedings of the Royal Society B: Biological Sciences, 276(1654):109.

Andersen, K. H. and Beyer, J. E. (2006). Asymptotic size determines species abundance in the marine size spectrum. The American Naturalist, 168:54-61.

Andersen, K. H., Jacobsen, N. S., and Farnsworth, K. D. (2016). The theoretical foundations for size spectrum models of fish communities. Canadian Journal of Fisheries and Aquatic Sciences, 73.

Andersen, K. H. and Pedersen, M. (2010). Damped trophic cascades driven by fishing in model marine ecosystems. Proceedings of the Royal Society B: Biological Sciences, 277(1682):795

Anderson, J. T. (1988). A review of size dependent survival during pre-recruit stages of fishes in relation to recruitment. Journal of Northwest Atlantic Fishery Science, 8:55-66.

Armstrong, M. J., Connolly, P., Nash, R. D. M., Pawson, M. G., Alesworth, E., Coulahan, P. J., Dickey-Collas, M., Milligan, S. P., O’Neill, M. F., Witthames, P. R., and Woolner, L. (2001). An application of the annual egg production method to estimate the spawning biomass of cod (Gadus morhua L.), plaice (Pleuronectes platessa L.) and sole (Solea solea L.) in the Irish Sea. ICES Journal of Marine Science, 58:183-203.

Barnes, C., Irigoien, X., De Oliveira, J., Maxwell, D., and Jennings, S. (2011). Predicting marine phytoplankton community size structure from empirical relationships with remotely sensed variables. Journal of Plankton Research, 33(1):13.

Batten, S., Walne, A., Edwards, M., and Groom, S. (2003). Phytoplankton biomass from continuous plankton recorder data: an assessment of the phytoplankton colour index. Journal of plankton research, 25(7):697. 
Beaugrand, G., Brander, K., Lindley, J., Souissi, S., and Reid, P. (2003). Plankton effect on cod recruitment in the North Sea. Nature, 426(6967):661-664.

Benoît, E. and Rochet, M. (2004). A continuous model of biomass size spectra governed by predation and the effects of fishing on them. Journal of Theoretical Biology, 226(1):9-21.

Blanchard, J., Dulvy, N., Jennings, S., Ellis, J., Pinnegar, J., Tidd, A., and Kell, L. (2005). Do climate and fishing influence size-based indicators of Celtic Sea fish community structure? ICES Journal of Marine Science: Journal du Conseil, 62(3):405.

Blanchard, J. L. (2000). Maternal contribution to the reproductive potential of a recovering fish stock: variability in the fecundity and condition of haddock (Melanogrammus aeglefinus) on the Scotian Shelf. Master's thesis, Dalhousie University.

Blanchard, J. L., Andersen, K. H., Scott, F., Hintzen, N. T., Piet, G., and Jennings, S. (2014). Evaluating targets and trade-offs among fisheries and conservation objectives using a multispecies size spectrum model. Journal of Applied Ecology, 51(3):612622.

Blanchard, J. L., Jennings, S., Holmes, R., Harle, J., Merino, G., Allen, J. I., Holt, J., Dulvy, N. K., and Barange, M. (2012). Potential consequences of climate change for primary production and fish production in large marine ecosystems. Philosophical Transactions of the Royal Society B: Biological Sciences, 367(1605):2979-2989.

Blanchard, J. L., Jennings, S., Law, R., Castle, M. D., McCloghrie, P., Rochet, M., and Benoît, E. (2009). How does abundance scale with body size in coupled sizestructured food webs? Journal of Animal Ecology, 78(1):270-280.

Blanchard, J. L., Law, R., Castle, M., and Jennings, S. (2011). Coupled energy pathways and the resilience of size-structured food webs. Theoretical Ecology, 4(3):289-300. 
Boudreau, P. and Dickie, L. (1992). Biomass spectra of aquatic ecosystems in relation to fisheries yield. Canadian Journal of Fisheries and Aquatic Sciences, 49(8):1528-1538.

Bowers, A. (1954). Breeding and growth of whiting (Gadus merlangus L.) in Isle of Man waters. Journal of the Marine Biological Association of the United Kingdom, 33(01):97122.

Brander, K. (1994). The location and timing of cod spawning around the British Isles. ICES Journal of Marine Science, 51(1):71.

Cózar, A. and Echevarría, F. (2005). Size structure of the planktonic community in microcosms with different levels of turbulence. Scientia Marina, 69(2):187-197.

Cury, P. and Pauly, D. (2000). Patterns and propensities in reproduction and growth of marine fishes. Ecological Research, 15(1):101-106.

Cushing, D. H. (1975). Marine ecology and fisheries. Cambridge University Press, Cambridge.

Cushing, D. H. and Horwood, J. W. (1994). The growth and death of fish larvae. Journal of Plankton Research, 16(3):291-300.

Datta, S. (2011). A mathematical analysis of marine size spectra. PhD thesis, The University of York.

Datta, S., Delius, G. W., and Law, R. (2010). A jump-growth model for predator-prey dynamics: derivation and application to marine ecosystems. Bulletin of Mathematical Biology, 72(6):1361-1382. Corrected version at http:/ / arxiv.org/abs/0812.4968.

De Roos, A. and Persson, L. (2001). Physiologically structured models: from versatile technique to ecological theory. Oikos, 94(1):51-71.

De Roos, A. and Persson, L. (2002). Size-dependent life-history traits promote catastrophic collapses of top predators. Proceedings of the National Academy of Sciences of the United States of America, 99(20):12907. 
De Roos, A. M., Galic, N., and Heesterbeek, H. (2009). How resource competition shapes individual life history for nonplastic growth: ungulates in seasonal food environments. Ecology, 90(4):945-960.

Duarte, C. and Alcaraz, M. (1989). To produce many small or few large eggs: a sizeindependent reproductive tactic of fish. Oecologia, 80(3):401-404.

Ejsmond, M. J., Varpe, Ø., Czarnoleski, M., and Kozłowski, J. (2015). Seasonality in offspring value and trade-offs with growth explain capital breeding. Ecological Research, 25(25):1-58.

Findlay, H. S., Yool, A., Nodale, M., and Pitchford, J. W. (2006). Modelling of autumn plankton bloom dynamics. Journal of Plankton Research, 28(2):209-220.

Fuchs, H. and Franks, P. (2010). Plankton community properties determined by nutrients and size-selective feeding. Marine Ecology Progress Series, 413:1-15.

Gasol, J. M., Guerrero, R., and Pedrós-Alió, C. (1992). Seasonal variations in size structure and procaryotic dominance in sulfurous Lake Cisó. Limnology and Oceanography, 36(5):860-872.

Hartvig, M., Andersen, K. H., and Beyer, J. E. (2011). Food web framework for sizestructured populations. Bulletin of Mathematical Biology, 272:113-122.

Heath, M. R. (1995). Size spectrum dynamics and the planktonic ecosystem of Loch Linnhe. ICES Journal of Marine Science, 52:627-642.

Horwood, J., Cushing, D., and Wyatt, T. (2000). Planktonic determination of variability and sustainability of fisheries. Journal of Plankton Research, 22(7):1419.

Huete-Ortega, M., Marañón, E., Varela, M., and Bode, A. (2010). General patterns in the size scaling of phytoplankton abundance in coastal waters during a 10-year time series. Journal of Plankton Research, 32(1):1-14. 
1 Hunter, E., Metcalfe, J., and Reynolds, J. (2003). Migration route and spawning area fidelity by North Sea plaice. Proceedings of the Royal Society of London. Series B: Biological Sciences, 270(1529):2097.

4 Huss, M., Gårdmark, A., Van Leeuwen, A., and De Roos, A. M. (2012). Size- and food-dependent growth drives patterns of competitive dominance along productivity gradients. Ecology, 93(4):847-857.

Jager, H. I., Rose, K. A., and Vila-Gispert, A. (2008). Life history correlates and extinction risk of capital-breeding fishes. Hydrobiologia, 602(1):15-25.

Jennings, S. and Mackinson, S. (2003). Abundance-body mass relationships in sizestructured food webs. Ecology Letters, 6:971-974.

Johnson, D. L. (2000). Preliminary examination of the match-mismatch hypothesis and recruitment variability of yellowtail flounder, Limanda ferruginea. Fisheries Bulletin, 98(4):854-863.

Jönsson, K. I. (1997). Capital and income breeding as alternative tactics of resource use in reproduction. Oikos, 78:57-66.

Knijn, R. J., Boon, T. W., Heessen, H. J. L., and Hislop, J. R. G. (1993). Atlas of North Sea Fishes: ICES Cooperative Research Report No. 194. ICES, Copenhagen, Denmark.

Kooijman, S. A. L. M. (1986). Energy budgets can explain body size relations. Journal of Theoretical Biology, 121:269-282.

Kooijman, S. A. L. M. (2009). Dynamic energy budget theory. Cambridge University Press, Cambridge, 3rd edition.

Kot, M. (2001). Elements of mathematical ecology. Cambridge Univ Press.

Lambert, Y. and Dutil, J.-D. (2000). Energetic consequences of reproduction in atlantic cod (gadus morhua) in relation to spawning level of somatic energy reserves. Canadian Journal of Fisheries and Aquatic Sciences, 57(4):815-825. 
Law, R., Plank, M. J., James, A., and Blanchard, J. L. (2009). Size-spectra dynamics from stochastic predation and growth of individuals. Ecology, 90(3):802-811.

Law, R., Plank, M. J., and Kolding, J. (2012). On balanced exploitation of marine ecosystems: results from dynamic size spectra. ICES Journal of Marine Science: Journal du Conseil, 69(4):602-614.

Le Cren, E. (1951). The length-weight relationship and seasonal cycle in gonad weight and condition in the perch (Perca fluviatilis). The Journal of Animal Ecology, 20(2):201219.

Leggett, W. and Deblois, E. (1994). Recruitment in marine fishes: is it regulated by starvation and predation in the egg and larval stages? Netherlands Journal of Sea Research, 32(2):119-134.

Longhurst, A. (1998). Cod: perhaps if we all stood back a bit? Fisheries Research, 38(2):101-108.

Mari, X. and Burd, A. (1998). Seasonal size spectra of transparent exoploymeric particles (tep) in a coastal sea and comparison eith those predicted using coagulation theory. Marine Ecology Progress Series, 163:63-76.

Marzloff, M., Shin, Y.-J., Tam, J., Travers, M., and Bertrand, A. (2009). Trophic structure of the peruvian marine ecosystem in 2000-2006: insights on the effects of management scenarios for the hake fishery using the ibm trophic model osmose. Journal of Marine Systems, 75(1):290-304.

Maury, O., Faugeras, B., Shin, Y.-J., Poggiale, C., Ari, T. B., and Marsac, F. (2007a). Modelling environmental effects on the size-structured energy flow through marine ecosystems. Part 1: the model. Progress in Oceanography, 74:479-499.

Maury, O. and Poggiale, J.-C. (2013). From individuals to populations to communities: 
A dynamic energy budget model of marine ecosystem size-spectrum including life history diversity. Journal of theoretical biology, 324:52 - 71 .

Maury, O., Shin, Y., Faugeras, B., Ben Ari, T., and Marsac, F. (2007b). Modeling environmental effects on the size-structured energy flow through marine ecosystems. Part 2: simulations. Progress in Oceanography, 74(4):500-514.

Menzel, D. W. and Ryther, J. H. (1960). The annual cycle of primary production in the Sargasso Sea off Bermuda. Deep Sea Research, 6:351-367.

Mertz, G. and Myers, R. A. (1994). Match/mismatch predictions of spawning duration versus recruitment variability. Fisheries Oceanography, 3(4):236-245.

Moloney, C. L. and Field, J. G. (1991). The size-based dynamics of plankton food webs. I. A simulation model of carbon and nitrogen flows. Journal of Plankton Research, 13(5):1003-1038.

Navarro, J. M. and Thompson, R. J. (1995). Seasonal fluctuations in the size spectra, biochemical composition and nutritive value of the seston available to a suspensionfeeding bivalve in a subarctic environment. Marine Ecology Progress Series, 125:95106.

Pedersen, T. and Jobling, M. (1989). Growth rates of large, sexually mature codi $i_{i}$ gadus morhua $\mathrm{i}_{\mathrm{i}} / \mathrm{i}_{\mathrm{i}}$, in relation to condition and temperature during an annual cycle. Aquaculture, 81(2):161-168.

Persson, L., Leonardsson, K., de Roos, A., Gyllenberg, M., and Christensen, B. (1998). Ontogenetic scaling of foraging rates and the dynamics of a size-structured consumer-resource model. Theoretical Population Biology, 54(3):270-293.

Platt, T. and Denman, K. (1978). The structure of pelagic marine ecosystems. Rapports et Procs-Verbaux Des Runions, Conseil International Pour l'Exploration de la Mer, 173:6065. 
1 Pope, J. G., Shepherd, J. G., Webb, J., Stebbing, A. R. D., and Mangel, M. (1994). Successful surf-riding on size spectra: The secret of survival in the sea [and discussion]. Philosophical Transactions: Biological Sciences, 343(1303):41-49.

4 Quéro, J. (1984). Les poissons de mer des pêches françaises. J. Grancher.

R (2015). R: A Language and Environment for Statistical Computing. R Foundation for Statistical Computing, Vienna, Austria.

Rice, J. and Gislason, H. (1996). Patterns of change in the size spectra of numbers and diversity of the north sea fish assemblage, as reflected in surveys and models. ICES Journal of Marine Science, 53(6):1214-1225.

Rochet, M.-J. and Benoît, E. (2012). Fishing destabilizes the biomass flow in the marine size spectrum. Proceedings of the Royal Society B: Biological Sciences, 279(1727):284-292.

Sainmont, J., Andersen, K. H., Varpe, Ø., and Visser, A. W. (2014). Capital versus income breeding in a seasonal environment. The American Naturalist, 184(4):466476.

San Martin, E., Irigoien, X., Harris, R. P., López-Arrutia, A., Zubkov, M. V., and Heywood, J. L. (2006). Variation in the transfer of energy in marine plankton along a productivity gradient in the Atlantic Ocean. Limnology and Oceanography, 51(5):20842091.

Scott, F., Blanchard, J., and Andersen, K. (2015). mizer: Multispecies size spectrum modelling in R. R package version 0.2. https://cran.r-project.org/web/ packages/mizer/index.html.

Sheldon, R. and Parsons, T. (1967). A continuous size spectrum for particulate matter in the sea. Journal of the Fisheries Research Board of Canada, 24(5):909-915.

Sheldon, R. W., Prakash, A., and Sutcliffe Jr., W. H. (1972). The size distribution of particles in the ocean. Limnology and Oceanography, 17(3):327-340. 
1 Sherman, K., Smith, W., Morse, W., Berman, M., Green, J., and Ejsymont, L. (1984).

Spawning strategies of fishes in relation to circulation, phytoplankton production, and pulses in zooplankton off the northeastern united states. Marine ecology progress series. Oldendorf, 18(1):1-19.

Shuter, B., Finstad, A., Helland, I., Zweimüller, I., and Hölker, F. (2012). The role of winter phenology in shaping the ecology of freshwater fish and their sensitivities to climate change. Aquatic Sciences, 74(4):637-657.

Sun, Z. and de Roos, A. M. (2015). Alternative stable states in a stage-structured consumer-resource biomass model with niche shift and seasonal reproduction. Theoretical population biology.

Truscott, J. E. (1995). Environmental forcing of simple plankton models. Journal of Plankton Research, 17(12):2207-2232.

van Leeuwen, A., Huss, M., Gårdmark, A., Casini, M., Vitale, F., Hjelm, J., Persson, L., and de Roos, A. M. (2013). Predators with multiple ontogenetic niche shifts have limited potential for population growth and top-down control of their prey. The American Naturalist, 182(1):53-66.

Ware, D. M. (1975). Relation between egg size, growth, and natural mortality of larval fish. Journal of the Fisheries Research Board of Canada, 32:2503-2512.

Woodworth-Jefcoats, P. A., Polovina, J. J., Dunne, J. P., and Blanchard, J. L. (2013). Ecosystem size structure response to 21st century climate projection: large fish abundance decreases in the central north pacific and increases in the california current. Global change biology, 19(3):724-733.

Wootton, R. (1977). Effect of food limitation during the breeding season on the size, body components and egg production of female sticklebacks (Gasterosteus aculeatus). Journal of Animal Ecology, 46(3):823-834. 
1 Zhou, M., Tande, K. S., Zhu, Y., and Sun̈nje Basedow (2009). Productivity, trophic 2 levels and size spectra of zooplankton in northern Norwegian shelf regions. Deep $3 \quad$ Sea Research II, 56:1934-1944. 


\section{Tables}

Table 1: Size spectrum model equations. Species-specific parameters are defined as follows for species $i$, in order of appearance: preferred predator prey mass ratio $=\beta_{i}$, width of prey size preference $=\sigma_{i}$, volumetric search rate $=\gamma_{i}\left(\mathrm{~g}^{-q} \mathrm{yr}^{-1}\right)$, maximum food intake rate $=h$ $\left(\mathrm{g}^{1-n} \mathrm{yr}^{-1}\right)$, interaction with species $j \theta_{i j}$, maturation weight $=w_{i}^{*}(\mathrm{~g})$, asymptotic weight $=$ $W_{i}(\mathrm{~g})$, standard metabolism $=k_{i}\left(\mathrm{~g}^{1-n} \mathrm{yr}^{-1}\right)$, population density $N_{i}$, estimated maximum recruitment parameters $=R_{\max . i}\left(\right.$ density $\left.\mathrm{yr}^{-1}\right)$, fishing selectivity parameter $=F_{i}$. Constants are defined as follows, in order of appearance: critical feeding level $=f_{0}$, exponent of search volume $=q$, exponent of maximum consumption $=n$, carrying capacity of resource spectrum $=\kappa_{r}$, assimilation efficiency $=\alpha$, exponent of standard metabolism $=p$, reproductive efficiency $=\epsilon$, egg weight $=w_{0}$, pre-factor for background mortality $=Z_{0}$, exponent of background mortality $=z$, fishing selectivity weights $=S 1$ and $S 2$, productivity of resource spectrum $=R_{0}$, exponent of resource spectrum $=\lambda$. For values of all parameters (except those related to seasonality) see Blanchard et al. (2014, Tables S2 and S5). For detailed information about the life processes modelled, see Scott et al. (2015, Section 3).

\section{Encounter and consumption}

Prey size selection

$$
\phi\left(\frac{w_{\text {prey }}}{w}\right)=\exp \left[-\left(\ln \left(\frac{\beta_{i} w_{\text {prey }}}{w}\right)\right)^{2} /\left(2 \sigma_{i}^{2}\right)\right]
$$

5 Volumetric search rate

$$
V_{i}(w)=\gamma_{i} w^{q} ; \gamma_{i}=\frac{f_{0} h_{i} \beta_{i}{ }^{n-q}}{\left(1-f_{0}\right) \sqrt{2 \pi} \kappa_{r} \sigma_{i}}
$$

6 Encountered food

$$
E_{i}(w)=V_{i}(w) \sum_{j} \theta_{i j} \int_{0}^{\infty} \phi\left(\frac{w_{\text {prey }}}{w}\right) N_{j}\left(w_{\text {prey }}\right) w_{\text {prey }} d w_{\text {prey }}
$$

7 Maximum consumption rate

$$
I_{\text {max. } i}=h_{i} w^{n}
$$

8 Feeding level

$$
f_{i}(w)=\frac{E_{i}(w)}{E_{i}(w)+I_{\max . i}}
$$

\section{Growth and reproduction}


1 Maturation function

$$
\psi_{i}(w)=\left[1+\left(\frac{w}{w_{i}^{*}}\right)^{-10}\right]^{-1}\left(\frac{w}{W_{i}}\right)^{1-n}
$$

2 Somatic growth

$$
\begin{aligned}
g_{i}(w) & =\left(\alpha f_{i}(w) I_{\text {max. }}-k_{i} w^{p}\right)\left(1-\psi_{i}(w) \cdot s\left(v_{i}, t_{i}, \psi_{i}(w), t\right)\right) \\
\min _{g_{i}(w)} & =0
\end{aligned}
$$

3 Egg production

$$
\begin{aligned}
g_{r}(w) & =\left(\alpha f_{i}(w) I_{\text {max. }}-k_{i} w^{p}\right) \psi_{i}(w) \cdot s\left(v_{i}, t_{i}, \psi_{i}(w), t\right) \\
\max _{g_{r}(w)} & =\alpha f_{i}(w) I_{\text {max } . i}-k_{i} w^{p}
\end{aligned}
$$

4 Time-dependent term

$$
s\left(v_{i}, t_{i}, \psi_{i}, t\right)=\frac{e^{\left(1-\psi_{i}(w)\right) v_{i} \cos \left(2 \pi\left(t-t_{i}\right)\right)}}{I_{0}\left(1-\psi_{i}(w) v_{i}\right)}
$$

\section{Recruitment}

6 Population egg production

$$
R_{p . i}=\epsilon /\left(2 w_{0} N_{i}\left(w_{0}\right) g\left(w_{0}\right)\right) \int_{w_{i}^{*}}^{w_{i}} N_{i}(w) g_{r}(w) d w
$$

7 Recruitment

$$
R_{i}=R_{\max . i} \frac{R_{p . i}}{R_{\text {max. } . i}+R_{p . i}}
$$

\section{Mortality}

9 Background mortality

$$
\mu_{0}=Z_{0} W_{i}^{z}
$$


1 Predation mortality

$$
\mu_{p . i}\left(w_{\text {prey }}\right)=\sum_{j} \int_{w_{0}}^{\infty} \phi\left(\frac{w_{\text {prey }}}{w}\right)\left(1-f_{j}(w)\right) V_{j}(w) \theta_{i j} N_{j}(w) d w
$$

2 Fishing selectivity

$$
S_{i}(w)=1 /\left(1+e^{(S 1-S 2 w)}\right)
$$

3 Fishing mortality

$$
\bar{F}_{i}(w)=S_{i}(w) F_{i}
$$

\section{Resource spectrum:}

5 Population dynamics

$$
\begin{aligned}
\frac{\partial N_{r}(w, t)}{\partial t}= & \left(\omega+(1-\omega) s\left(v_{p}, t_{p}, \psi_{p}, t\right)\right) \\
& \left(R_{0} w^{n-1}\left[\kappa(w)-N_{r}(w, t)\right]-\mu_{p . r}(w) N_{r}(w, t)\right)
\end{aligned}
$$

6 Carrying capacity

$$
\kappa(w)=\kappa_{r} w^{-\lambda}
$$


Table 2: Parameter values used for seasonal processes in the model. The shape of plankton blooms is taken from empirical data sources (Gasol et al. 1992; Huete-Ortega et al. 2010). Parameters related to spawning are fitted to species-specific spawning data (Figure 1); numbers refer to species in order, from left to right and then top to bottom.

\begin{tabular}{|c|c|c|}
\hline Term & Definition & Value (with units) \\
\hline \multirow{4}{*}{$v_{i}$} & Spawning behaviour & {$[3.6047,2.9994,1.944,1.141$,} \\
& severity of spawning peaks & $0.40493,0.795,4.973,1.4257$, \\
& & $4.0495,3.6567,5.4732,1.951]$ \\
& & or all 0 (non-seasonal) \\
$t_{i}$ & time of spawning peaks & {$[0.5477,0.0643,0.3574,0.3825$,} \\
& & $0.8576,0.5021,0.4856,0.3716$, \\
& & $0.2245,0.4181,0.3123,0.3333]$ \\
$v_{p}$ & Plankton blooms & 30, or 0 (non seasonal) \\
$t_{p}$ & severity of plankton bloom & 0.4 \\
$\psi_{p}$ & time of bloom peak & 0 \\
$\omega$ & proportion of plankton away from bloom & 0.7 \\
\hline
\end{tabular}




\section{Figure captions}

2 Figure 1, Fitting von Mises distributions to the twelve fish species simulated in the 3 model. The fit consists of two parameters for each species $i$ : the time of maximum spawning $t_{i}$ and the severity of the spawning peak $v_{i}$. The species are, in increasing 5 asymptotic size from left to right and top to bottom: sprat, sandeel, Norway pout, 6 dab, herring, grey gurnard, sole, whiting, plaice, haddock, cod and saithe. Data aggregated from Bowers (1954); Quéro (1984); Alheit (1988); Knijn et al. (1993); Albert (1994); Brander (1994); Hunter et al. (2003).

9 Figure 2. The size spectrum after 500 years, with non-seasonal and seasonal processes in place. (a) Comparing the community spectra for non-seasonal (dashed black line) and seasonal (solid grey line) systems. Also included for reference is the non-seasonal resource spectrum (dotted black line at left side of the spectrum). (b) The seasonal size spectrum after 500 years; community spectrum given by solid black line, individual 4 species spectra shown by dashed grey lines. Asymptotic size of each species marked 5 by black squares.

Figure 3. The bi-monthly size spectra over a year for the twelve fish species in a seasonal system, relative to their (non-seasonal) steady state abundances (horizontal black lines), to elucidate the differences between the systems. Months are plotted in different colours to allow comparison between times and species.

Figure 4. The growth curves (calculated using the method of characteristics (3)) for offspring of different species hatching into spectra in both non-seasonal (dashed grey lines) and seasonal (solid black lines) systems, over 15 years.

Figure 5. The growth trajectory for a mature sole individual in a seasonal environment (solid black line), compared with a similar sized individual in a non-seasonal environment (dashed grey line). Shown for reference is the spawning function for sole (dotted black curve), taken from Figure 1 . 
1 Figure 6. The effect of altering fishing intensity after a year on (a) the community 2 spectrum slope, and (b) total fishing yields. Non-seasonal spectra shown in black, 3 seasonal in grey; solid lines indicate doubling fishing intensity, dashed lines indicate 4 halving, and dot-dash lines indicate maintaining baseline fishing effort. The baseline 5 fishing effort consists of estimates used to calibrate the model across the 1985-1995 6 time period and cross-validation was shown to give realistic time-averaged species 7 size distributions and growth in non-seasonal species spectra (Blanchard et al. 2014).

8 Figure 7 The abundance of individuals for non-seasonal and seasonal systems over 9 ten years with baseline fishing effort, once systems have reached regular inter-annual 10 patterns. Shown are total number densities for organisms (a) less than $40 \mathrm{~g}$, and (b) 11 greater than or equal to $40 \mathrm{~g}$. Black solid lines indicate non-seasonal systems, and grey dashed lines indicate seasonal systems. 


\section{Figures}
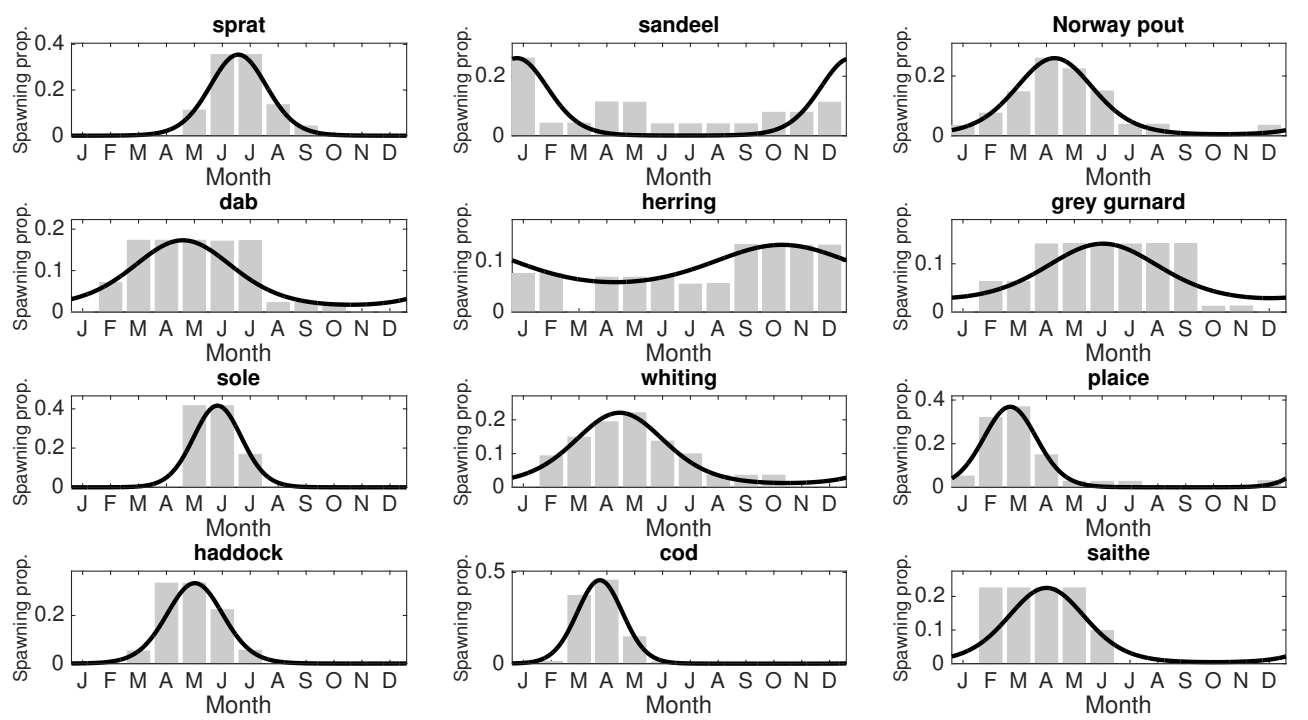

Figure 1: Figure 1. Fitting von Mises distributions to the twelve fish species simulated in the model. The fit consists of two parameters for each species $i$ : the time of maximum spawning $t_{i}$ and the severity of the spawning peak $v_{i}$. The species are, in increasing asymptotic size from left to right and top to bottom: sprat, sandeel, Norway pout, dab, herring, grey gurnard, sole, whiting, plaice, haddock, cod and saithe. Data aggregated from Bowers (1954); Quéro (1984); Alheit (1988); Knijn et al. (1993); Albert (1994); Brander (1994); Hunter et al. (2003). 
(a)

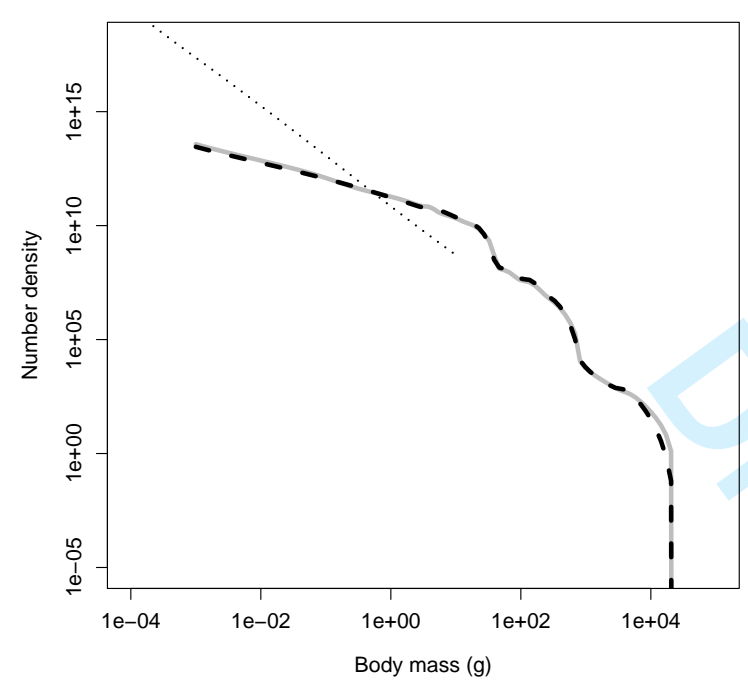

(b)

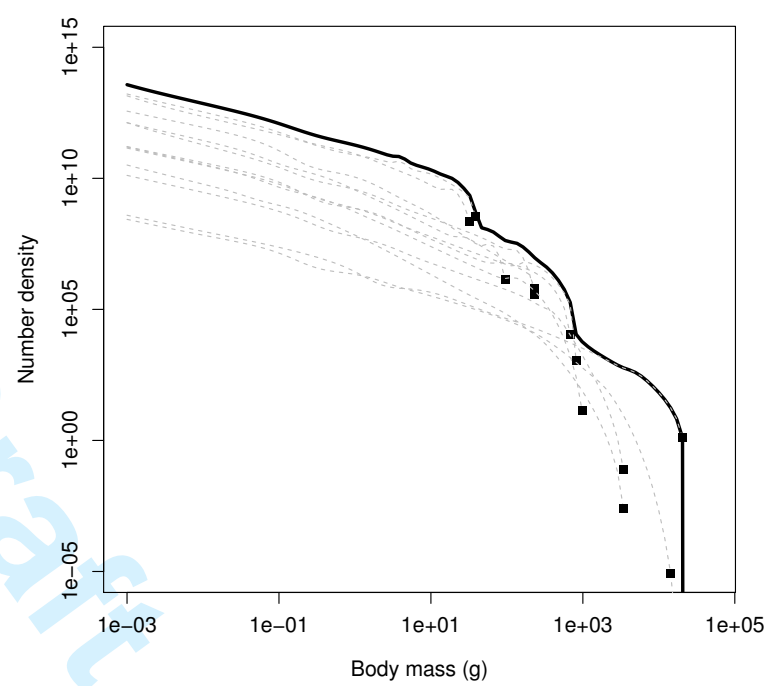

Figure 2: The size spectrum after 500 years, with non-seasonal and seasonal processes in place. (a) Comparing the community spectra for non-seasonal (dashed black line) and seasonal (solid grey line) systems. Also included for reference is the non-seasonal resource spectrum (dotted black line at left side of the spectrum). (b) The seasonal size spectrum after 500 years; community spectrum given by solid black line, individual species spectra shown by dashed grey lines. Asymptotic size of each species marked by black squares. 


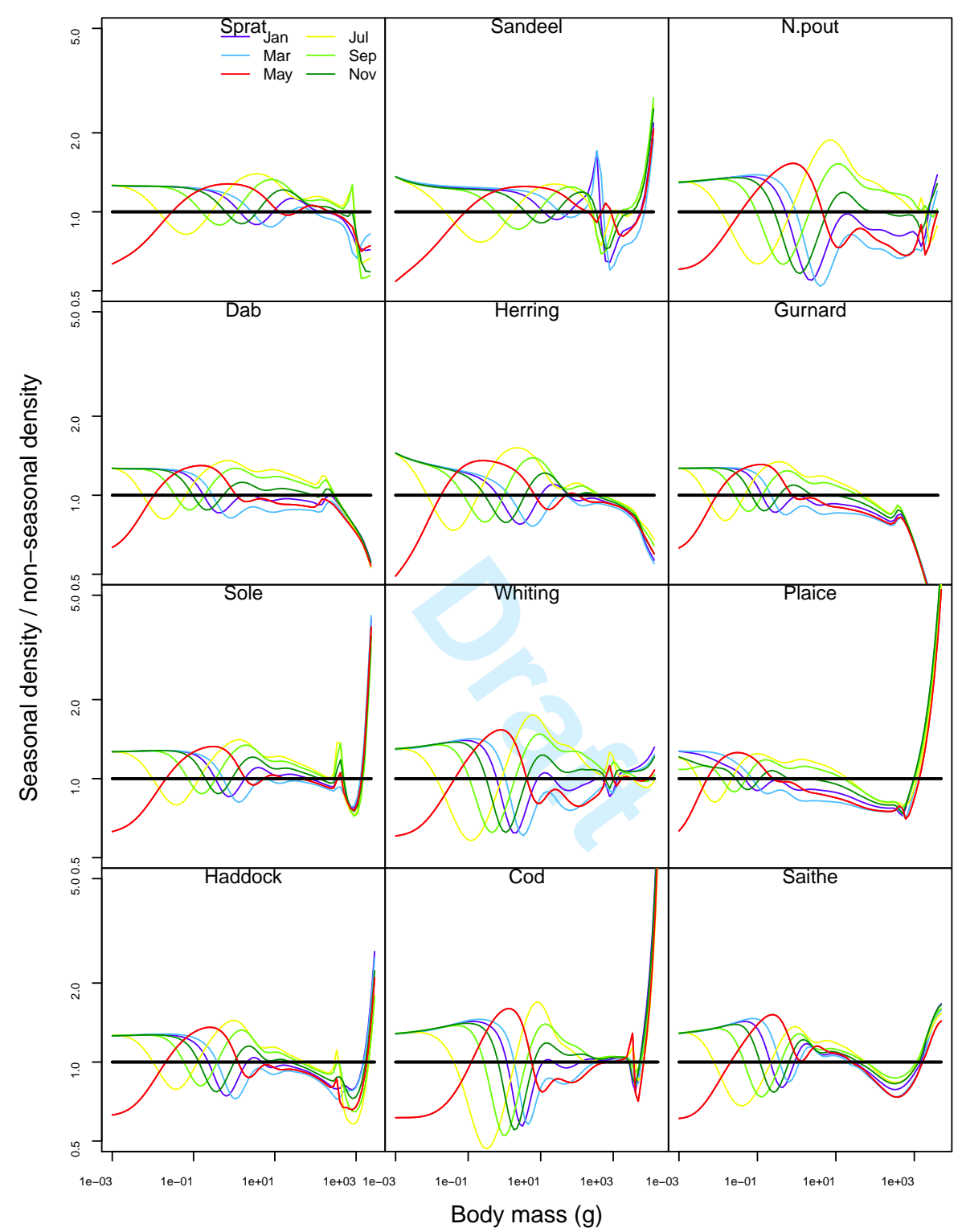

Figure 3: The bi-monthly size spectra over a year for the twelve fish species in a seasonal system, relative to their (non-seasonal) steady state abundances (horizontal black lines), to elucidate the differences between the systems. Months are plotted in different colours to allow comparison between times and species. 


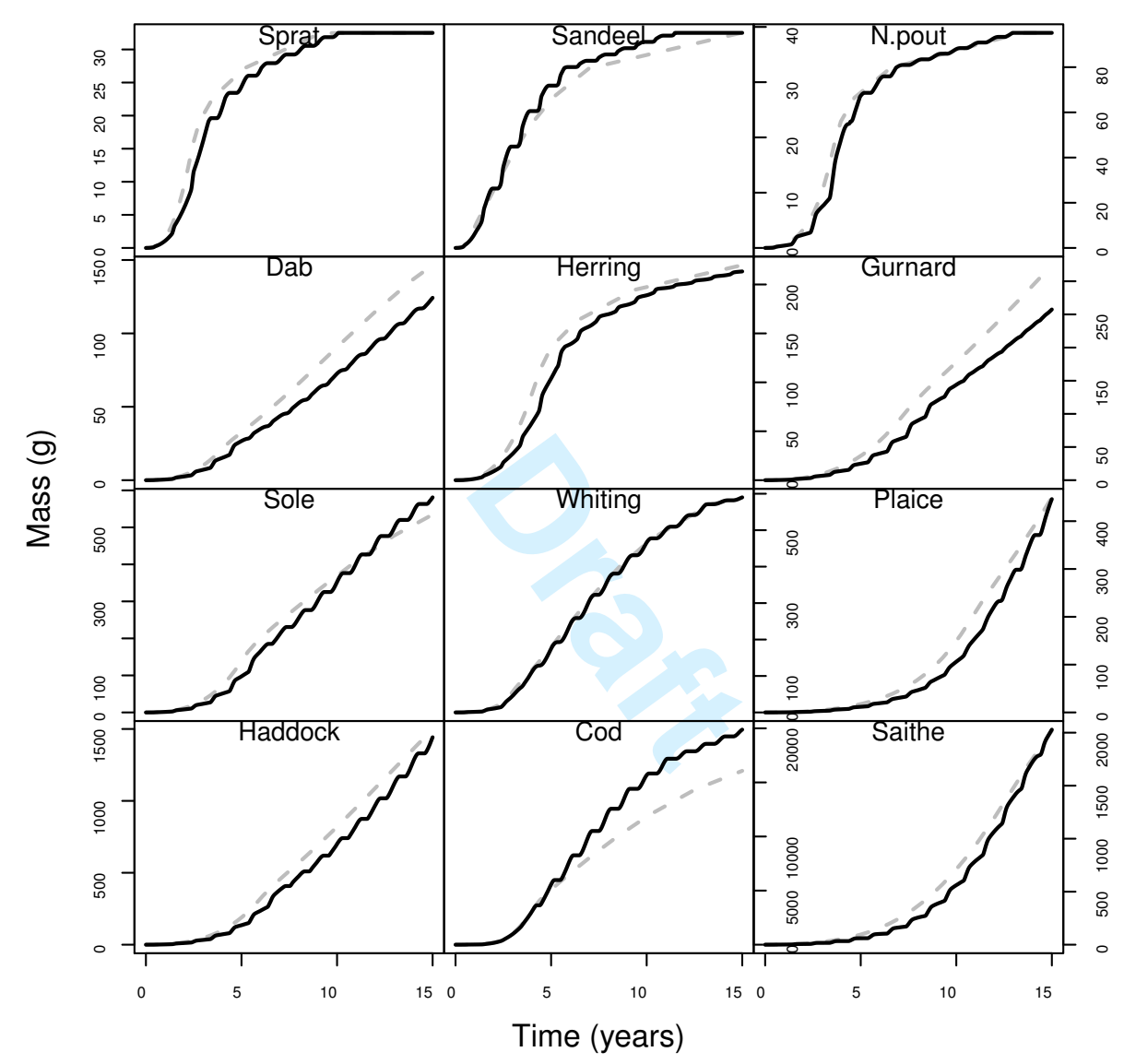

Figure 4: The growth curves (calculated using the method of characteristics (3)) for offspring of different species hatching into spectra in both non-seasonal (grey dashed lines) and seasonal (black solid lines) systems, over 15 years. 


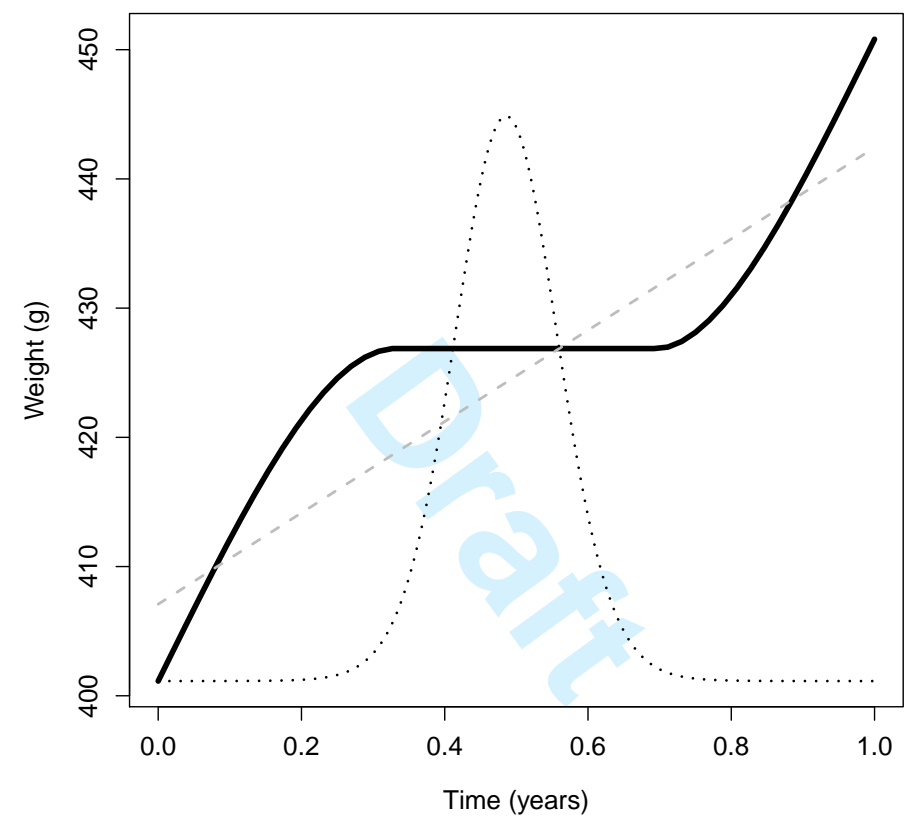

Figure 5: The growth trajectory for a mature sole individual in a seasonal environment (solid black line), compared with a similar sized individual in a non-seasonal environment (dashed grey line). Shown for reference is the spawning function for sole (dotted black curve), taken from Figure 1. 
(a)

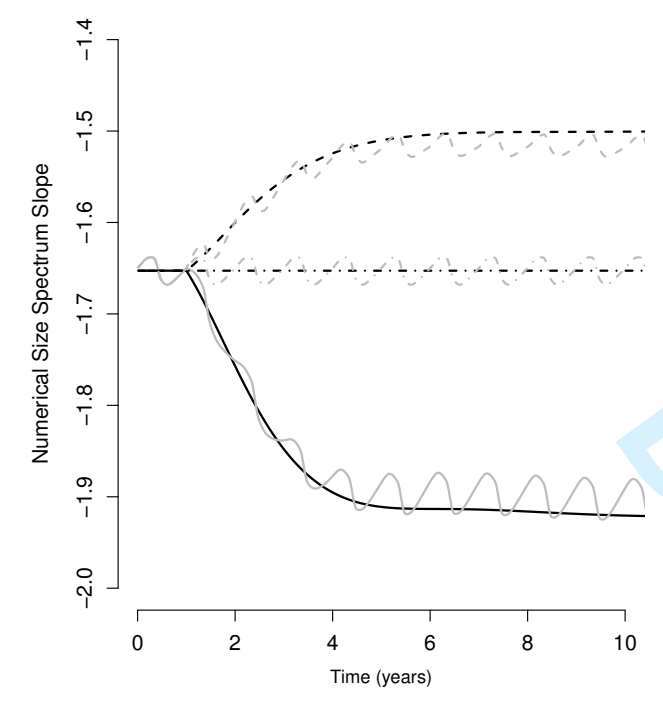

(b)

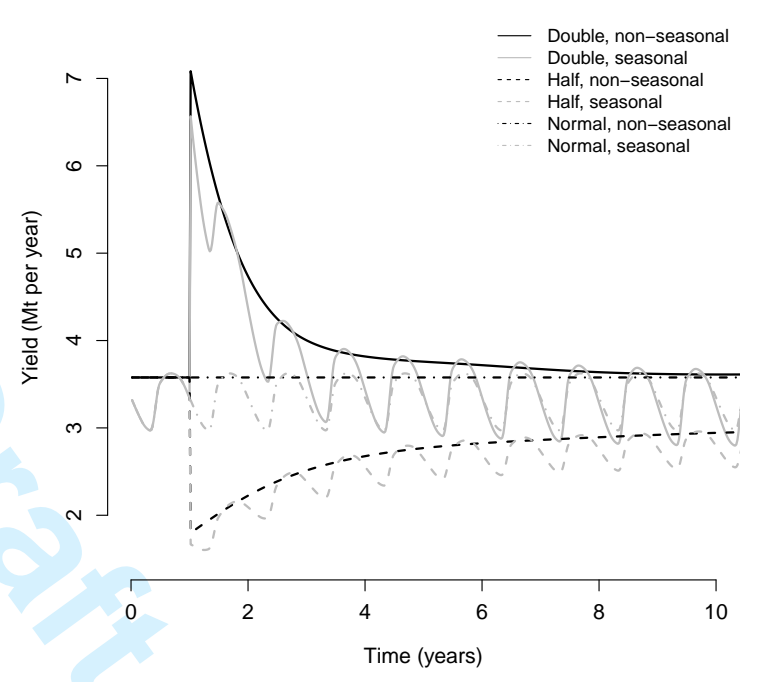

Figure 6: The effect of altering fishing intensity after a year on (a) the community spectrum slope, and (b) total fishing yields. Non-seasonal spectra shown in black, seasonal in grey; solid lines indicate doubling fishing intensity, dashed lines indicate halving, and dot-dash lines indicate maintaining baseline fishing effort. The baseline fishing effort consists of estimates used to calibrate the model across the 1985-1995 time period and cross-validation was shown to give realistic time-averaged species size distributions and growth in non-seasonal species spectra (Blanchard et al.|2014). 


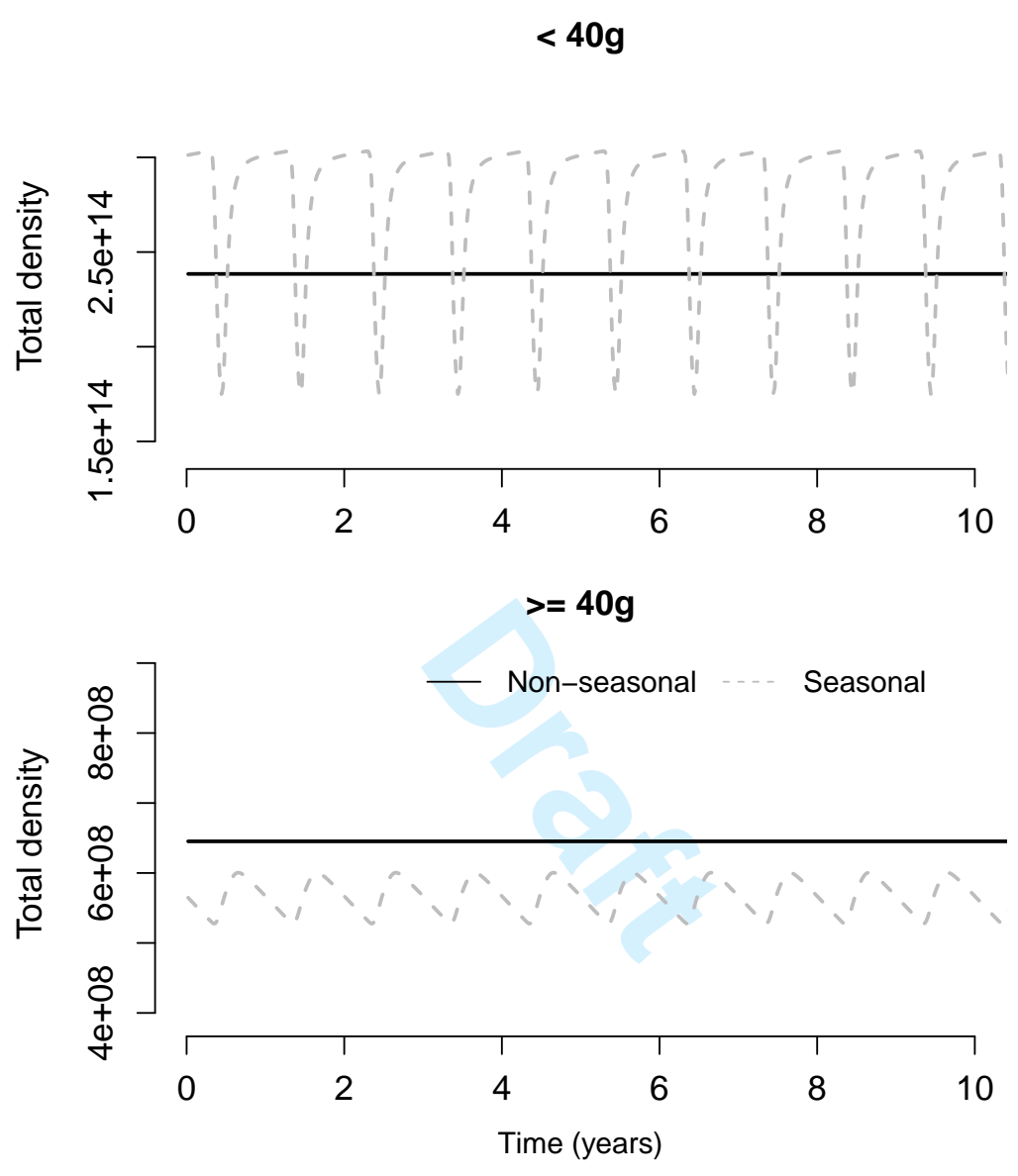

Figure 7: The abundance of individuals for non-seasonal and seasonal systems over ten years with baseline fishing effort, once systems have reached regular inter-annual patterns. Shown are total number densities for organisms (a) less than $40 \mathrm{~g}$, and (b) greater than or equal to $40 \mathrm{~g}$. Black solid lines indicate non-seasonal systems, and grey dashed lines indicate seasonal systems. 